\title{
MASALAH SOSIAL DAN SOCIAL DEMAND DALAM AKSESIBITLAS PENDIDKAN
}

\section{SOCIAL PROBLEM AND SOCIAL DEMAND IN EDUCATIONAL ACCESSIBILITY}

\author{
Omon Abdurakhman ${ }^{1 a}$, Irman Suherman ${ }^{1}$, Siti Pupu Fauziah ${ }^{1}$ \\ ${ }^{1 a}$ Manajemen Pendidikan Islam, Fakultas Keguruan dan Ilmu Pendidikan, Universitas Djuanda \\ ${ }^{a}$ Korespondensi: Omon Abdurakhman, Telp/Hp: 081299447669, E-mail: \\ omon.abdurakhman@unida.ac.id
}

\begin{abstract}
Mean Years School (MYS) Bogor district in 2018 amounted to 7,82 years. Means to obligated learn 9 year in Bogor district to 2018 not yet reached. Moreover, if looking policy 12 years in obligated learn of base education. The big mission for district governance to upgrading education level as effort to creat Indonesian excellent human resources. Knowing to cause of drop out or unable of society to educational access is very important, in order to find best solutions of solve the problem it. The research objective is create schematic for explain to cause of drop out in Bogor district. It use survey method to 11 subdistrict with amount 184 people respondent. The result it is cause of drop out or unable to educational access in Bogor district, 1) Educational costs are unaffordable, 2) Interest to join traditional pesantren is very high, 3) More choose to work, cause to aid family economic, 4) bullying in school, 5) the child don't school interest, 6) bad social intercourse, 7) a women; more choose is married, and 8) the opinion of social environmental is unembarrassing, if no schooling. The highest cause is why people drop out or unable to educational access is educational costs are unaffordable.
\end{abstract}

Keywords: Social Problem, Social Demand, Educational Accessibility, Mean Years School (MYS).

\begin{abstract}
ABSTRAK
Rata-rata Lama Sekolah (RLS) Kabupaten Bogor pada 2018 sebesar 7,82 tahun. Artinya sampai pada tahun 2018 wajib belajar 9 tahun belum dapat dicapai di Kabupaten Bogor. Apalagi jika melihat kebijakan Wajib Belajar Pendidikan Dasar (WBPD) 12 tahun. Merupakan tugas besar bagi pemerintah daerah untuk dapat meningkatkan taraf pendidikan, sebagai upaya mewujudkan SDM unggul Indonesia. Mengetahui penyebab putus sekolah atau ketidak mampuan masyarakat mengakses pendidikan menjadi penting, agar dapat menemukan solusi yang tepat untuk menyelesaikan masalah tersebut. Tujuan penelitian ini adalah membuat skema yang menggambarkan penyebab putus sekolah masyarakat di Kabupaten Bogor. Penelitian ini menggunakan metode survey pada 11 kecamatan dengan jumlah responden 184 orang. Berdasarkan hasil penelitian didapatkan bahwa penyebab mengapa masyarakat putus sekolah dan atau tidak dapat sekolah di Kabupaten Bogor adalah 1) Tidak ada biaya/Biaya yang tidak terjangkau, 2) Tingginya minat masuk pondok pesantren tradisional, 3) Seorang anak dari keluarga tidak mampu lebih memilih bekerja karena ingin membantu perekonomian keluarga, 4) Bullying di Sekolah, 5) Anak tidak mau sekolah, 6) Pergaulan yang tidak baik, 7) Menikah bagi perempuan, dan 8) Lingkungan masyarakat yang memandang jika tidak sekolah bukah hal yang memalukan. Penyebab tertinggi kenapa masyarakat
\end{abstract}


putus sekolah dan atau tidak dapat sekolah adalah tidak adanya biaya untuk sekolah karena biaya pendidikan tidak terjangkau..

Kata kunci: Masalah Sosial, Social Demand, Aksesibilitas Pendidikan, Rata-rata Lama Sekolah (RLS)

Abdurakhman, O., Suherman, I., \& Fauziah, R.S.P, (2019). Masalah Sosial Dan Social Demand Dalam Aksesibitlas Pendidkan, Tadbir Muwahhid, 3(2), 183-193

\section{PENDAHULUAN}

Pendidikan merupakan bidang yang menjadi sorotan utama dalam rencana pembangunan, baik pada tingkat wilayah maupun tingkat nasional. Pembangunan di bidang pendidikan ini bermuara pada perwujudan bangsa yang cerdas, berkualitas, berkarakter dan berdaya saing (Multilateral Meeting dalam Rangka Penyusunan RKP 2017 prioritas nasional, pembangunan pendidikan). kultur dan budaya, perbedaan georgrafis, serta keadaan sosial ekonomi yang bertingkat pada masing-masing daerah menyebabkan perbedaan permintaan atau tuntutan masayarakat (social demand) akan kebutuhan pendidikan yang pada akhirnya pemerintah juga akan membuat kebijakan yang berbeda di suatu daerah dengan daerah lainnya. Perbedaan antar tuntutan dan ketersediaan fasilitas dan sarana pendidikan ini, menyebabkan kesenjangan akan aksesibilitas masyarakat terhadap pendidikan.

Social Demand (kebutuhan masyarakat) adalah pendekatan yang digunakan dalam menyusun rencana pengembangan Pendidikan dengan memperhatikan kebutuhan masyarakat dalam haknya memperoleh Pendidikan, yakni kebutuhan Pendidikan berdasarkan jumlah masyarakat usia sekolah di suatu tempat, pada waktu tertentu, didalam budaya politik dan ekonomi tertentu (Coombs, 1982). Pendekatan perencanaan pendidikan melalui social demand ini lebih menekankan pada pemerataan kesempatan dalam mendapatkan pendidikan. Tugas perencana pendidikan dalam hal ini adalah menganalisis kebutuhan pada masa yang akan datang dengan menganalisa pertumbuhan penduduk, partisipasi masyarakat dalam pendidikan, arus siswa dan keinginan masyarakat (Sa'ud \& Makmudn, 2011).

Pada kasus dimana jumlah penduduk usia sekolah lebih bayak dibandingkan dengan jumah ruang kelas, maka dapat dikatakan tuntutan sosial melebihi apa yang tersedia. Disanalah perencanaan pengembangan Pendidikan melalui Socian Demand Approach dibutuhkan. Namun perlu diamati bahwa mengukur tuntutan masyarakat ini adalah hal paling sulit jika dikaitkan dengan tuntutan masyarakat yang muncul sebagai dampak dari kebijakan wajib belajar.

Khususnya di Kabupaten Bogor, memiliki masalah tersediri dalam bidang pendidikan. 
Rata-rata Lama Sekolah (RLS) Kabupaten Bogor pada 2018 sebesar 7,82 tahun. Artinya sampai pada tahun 2018 wajib belajar 9 tahun belum dapat dicapai di Kabupaten Bogor. Apalagi jika melihat kebijakan Wajib Belajar Pendidikan Dasar (WBPD) 12 tahun. Program Bogor cerdas (Bodas) kabupaten Bogor yang bertujuan untuk membentuk insan cedikia yang cerdas secara IPTEK akan menjadi mustahil jika RLS tahun-tahun selanjutnya masih rendah seperti itu.

Aksesibillitas Pendidikan adalah jalan masuk kedalam dunia pedidikan dengan tujuan mengikuti dan memanfaatkan fasilitas pendidikan sesuai dengan jalur, jenis dan jenjang Pendidikan di Indonesia. Ada tiga jenjang Pendidikan dari jalur pendidikan formal yaitu pendidikan dasar, pendidikan menengah dan pendidikan tinggi dan pendidikan yang wajib sebagai standar minimal pendidikan di Indonesia adalah wajib belajar 12 tahun yaitu Sekolah Dasar (SD), Sekolah Menengah Pertama (SMP) dan Sekolah Menengah Atas (SMA). Mengutif dalam Undang-undang No 20 tahun 2003 tentang SISDIKNAS menyatakan warga negera memiliki hak untuk mendapatkan pendidikan sekali pun bagi mereka yang memiliki kelainan fisik. Bahkan pada pasal 5 menegaskan bahwa setiap warga negera memiliki hak untuk meningkatkan pendidikannya sepanjang hayat.
Beberapa upaya telah dilakukan oleh Kabupaten Bogor untuk meingkatkan aksesibilitas Pendidikan diantaranya, membuat Ruang Kelas Baru (RKB) atau rehabilitasi sekolah sebagai upaya penyediaan sarana dan prasarana pendidikan sehingga bisa lebih banyak menampung peserta didik, penguatan sekolah melalui sekolah terbuka jenjang SMP/SMA, sekolah jarak jauh dan sekolah satu atap sebagai upaya pemberian fasilitas pendidikan bagi masyarakat yang tidak bisa mengakses pendidikan secara langsung.

Maka mengetahui penyebab dan alasan mengapa masyarakat tidak dapat mengakses pendidikan dan atau putus sekolah di tengah jalan menjadi solusi pertama dalam upaya peningkatan aksesibilitas pendidikan kedepan. Sehingga selanjutnya pemerintah daerah dapat membuat kebijakan yang sesuai dengan kondis masyarakat saat ini, terlebih sesuai dengan tuntutan dan kebutuhan semua kalangan masyarakat. Terutama bagi masyarakat pedesaan yang taraf ekonominya menengah ke bawah.

\section{METODE}

\section{Jenis Penelitian}

Penelitian ini merupakan penelitian lapangan (field research) dengan menggunakan metode survey (Sugiyono, 2015) pada 184 orang responden di 11 kecamatan, Kabupaten Bogor. 


\section{Waktu dan Tempat Penelitian}

Penelitian ini dilaksanakan di Kabupaten Bogor sejak bulan maret sampai bulan september 2019.

\section{Target/Subjek Penelitian}

Target/subjek penelitian adalah seluruh masyarakat di Kabupaten Bogor, sedangkan sampel yang diambil untuk menjadi responden adalah orang tua (bapak/ibu) dari setiap KK yang memiliki anak usia sekolah di 11 kecamatan Kabupaten Bogor.

\section{Prosedur Penelitian}

Metode penelitian yang digunakan adalah mix method dimana data hasil penelitian analisis secara kualitatif kemudian dilanjugkan dengan analisis kuantitatif untuk mendapatkan gambaran tentang masalah sosial dan social demand dalam aksesibilitas pendidikan di Kabupaten Bogor.

\section{Data, Instrumen, dan Teknik Pengumpulan Data}

Data tentang masalah sosial dan social demand dalam aksesibilitas pendidikan di Kabupaten Bogor didapatkan melalui observasi dan wawanara mendalam (indepth interview) dengan menggunakan panduan wawancar pada orang tua (bapak/ibu) dari setiap KK yang memiliki anak usia sekolah.

\section{Teknik Analisis Data}

Analisis kualitatif dilakukan terhadap data tentang persalahan sosial dan social demand yang berdampak pada akses pendidikan di
Kabupaten Bogor selanjutnya dihitung dengan pendekatan kuantitatif agar dapat dibuat skematis permasalah sosial dan social demand yang paling mendominasi sampai pada tingkat terendah.

\section{HASIL PENELITIAN DAN PEMBAHASAN}

\section{Hasil}

\section{Social Demand dan Masalah Sosial}

Berdasarkan hasil wawancara pada 184 responden menyatakan bahwa masalah sosial tertinggi yang menyebabkan putus sekolah adalah karena biaya pendidikan yang tidak terjangkau karena kondisi ekonomi yang kurang baik (36\%). Dana Bantuan Operasional Sekolah (BOS) yang diberikan pemerintah dianggap belum mampu menjawab tantangan tersebut. Siswa penerima BOS tetap harus menyiapkan dana untuk perlengkapan sekolah seperti, buku, baju seragam dan bahkan uang transport karena jarak sekolah yang jauh.

Selain masalah biaya sekolah, masyarakat juga mengalami masalah lain, yaitu anak tidak mau sekolah dibarengi dengan kurangnya perhatian dari orang tua terhadap hal tersebut (perhatian) merupakan penyebab kedua (19\%). Kondisi ini sangat mengkhawatirkan, karena orang tua yang seharusnya menjadi pendorong untuk anak-anak sekolah, pada 
kasus ini malah membiarkan atau tidak peduli ketika anaknya tidak mau sekolah.

Pergaulan yang kurang baik yang dilakukan oleh siswa (17\%), hal ini menyebabkan siswa menjadi malas untuk sekolah dan pada akhirnya dorp out. Selain itu juga siswa menjadi nakal, sehingga siswa harus di keluarkan oleh sekolah. Dengan seringnya pindah sekolah siswa menjadi ogah-ogahan dan menyebabkan putus sekolah di tengah jalan. Masalah kenakalan siswa di dalam atau di luar sekolah ini terkadang disebabkan oleh pergaulan siswa yang salah.

Selin itu, alasan yang relatif merata yaitu Tingginya minat masuk pondok pesantren tradisional, dan hal ini juga sebagai peralihan karena tidak mampunya membiayai sekolah di sekolah formal sehingga belajar di pondok pesantren sebesar 11\%. Bahkan ada yang memang keluarganya tidak mengijinkan belajar (sekolah) selain di pesantren. Masalah social lainnya adalah seorang anak dari keluarga tidak mampu secara ekonomi lebih memilih bekerja karena ingin membantu perekonomian keluarga, masalah ini sebesar $7 \%$ dari hasil wawancara responden.

Pandangan masyarakat di Kabupaten Bogor masih ada yang memiliki pandangan bahwa setinggi apapun pendidikan seorang anak perempuan, setelah menikah akan kembali juga mengurus rumah tangga, anak dan keluarganya di rumah. Sehingga memilih menikah khususnya bagi perempuan sebesar
$6 \%$ menjadi masalah sosial lainnya dalam aksesibilitas pendidikan.

Tingkat paling rendah yang menyebabkan putus sekolah dan tidak mau sekolah masyarakat Kabupaten Bogor berdasarkan data pada sampel penelitian adalah adanya bullying di sekolah yaitu sebesar $2 \%$, dimana hal ini membuat siswa merasa tidak aman dan nyaman pergi ke sekolah, sehingga ia menjadi malas dan akhirnya dropout. dan lingkungan masyarakat yang memandang jika tidak sekolah bukah hal yang memalukan $1 \%$.

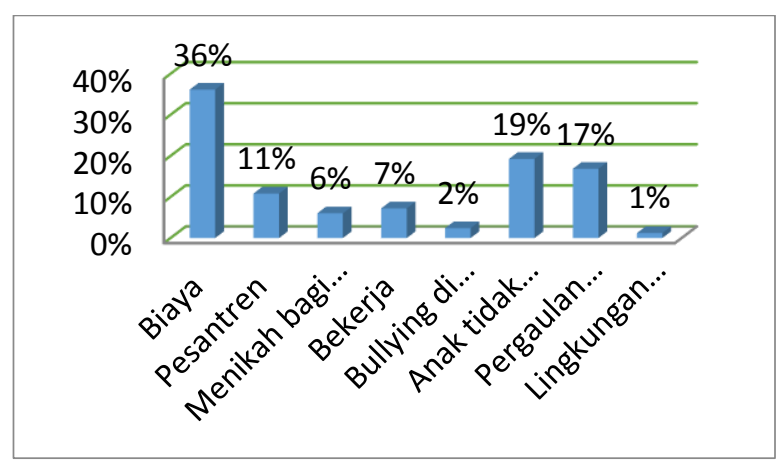

Gambar 1. Skematis Permasalahan Sosial dalam Aksesibilitas Pendidikan

Hasil penelitian lain pada aspek social demand menunjukkan bahwa ada lima bidang kebutuhan prioritas masyarakat dalam aksesibilitas pendidikan, yaitu finansial (dana), sarana dan prasarana (infrastruktur), SDM (guru dan tenaga kependidikan), lingkungan sekolah dan vokasi (pendampingan).

Kebutuhan sekaligus tuntutan masyarakat atas keterjangkauan biaya pendidikan menjadi prioritas utama dimana (71\%) masyarakat 
mengalami masalah di bidang ini juga sekaligus menjadi hal yang dibutuhkan untuk dapat tetap mengakses pendidikan. Kemudian kebutuhan dan tuntutan lain yang tidak kalau tinggi adalah terpenuhinya sarana dan prasarana (infrastruktur) pendidikan (24\%). Sekolah yang dekat dengan rumah menjadi penting, karena di pedesaan ketersediaan sekolah menjadi masalah besar dimana mereka harus berjalan kaki atau menaiki kendaraan untuk dapat ke sekolah, sedangkan ketersediaan transportasi umum juga tidak terpenuhi. Akahirnya masyarakat hanya mengenyam pendidkan sampai pada sekolah yang tersedia di daerahnya.

Kebutuhan lain bagi sekolah-sekolah yang ada di Kabupaten Bogor adalah terpenuhinya SDM (guru dan tenaga kependidikan) yang berkualitas $(3 \%)$. Hal ini menjadi anggapan bahwa guru-guru yang berkualitas akan meningkatkan minat siswa dalam belajar dan sekolah. Begitu juga kenyamanan dan kepuasan pelayanan tenaga kependidikan (staf) menjadi penting untuk dapat meningkatkan aksesibilitas pendidikan.

Selin itu, keamanan lingkungan sekolah (1\%) dan vokasi (pendampingan) tentang pentingannya pendidikan bagi masyarakat (1\%), menjadi kebutuhan lain agar dapat meningkatkan aksesibilitas pendidikan di Kabupaten Bogor.

\section{Kondisi Pendidikan di Kabupaten Bogor}

Pemerintah daerah setiap tahunnya selalu mengembangkan program dalam upaya meningkatkan partisipasi masyarakat pada pendidikan. Rendahnya Rata-rata Lama Sekolah (RLS) di kabupaten Bogor membuat pemerintah daerah berpikir keras untuk meningkatkan nilai RLS tersebut. Beberapa strategi yang telah dibuat dan telah dilaksanakan antara lain:

1. Memperluas daya tampung atau aksesibilitas anak untuk sekolah melalui program RKB dan rehabilitas sekolah

2. Penguatan sekolah alternatif; (Terbuka jenjang SMP/SMA, kelas jauh dan sekolah satu atap)

3. Mengaktifkan kelompok PKBM

4. Mendorong pendidikan kesetaraan (Pake A, B, C) dan program Keaksaraan Fungsional (KF)

5. Meningkatkan koordinasi dan kerjasama dengan sekolah swasta dalam rangka memperluas jangkauan kegiatan belajar mengajar

6. Merintis kegiatan desa mengajar

7. Mengembangkan gerakan desa mengajar di Pondok Pesantren

8. Mengaktifkan kemabali SATGAS sekolah

9. Bekerjasama dengan perguruan tinggi dalam meingkatkan pemahaman tentang pentingnya pendidikan melalui kegiatan KKN mahasiswa.

Upaya meningkatkan RLS di Kabupaten Bogor yang pertama adalah program RKB dan rehabilitas sekolah. Namun ada hal lain yang harus diamati dimana ketersediaan sekolah apakah sudah sangat mencukupi atau belum. Atau infrastruktur pendidikan di sekolah 
apakah sudah sangat mendukung dalam aksesibilitas anak untuk sekolah. Karena berdasarkan observasi dan pengakuan dari masyarakat masih ada kendalam jarak sekolah dari rumah sangat jauh, sehingga hal tersebut menjadi salah satu penyebab putus sekolah dan atau tidak dapat sekolah.

Gambaran ketersediaan sekolah pada setiap jenjang dan jenis sekolah di kabupaten Bogor dapat dilihat pada tabel-tabel di bawah ini:

Table 1. Jumlah Sekolah Dasar (SD) dan Sekolah Menengah Pertama (SMP) di Kabupaten Bogor, 2017

\section{Number of Primary Schools and Junior}

High Schools in Bogor Regency, 2017

\begin{tabular}{|c|c|c|c|c|}
\hline No & Tingkat/ Status & Negeri & Swasta & Jumlah \\
\hline \multirow[t]{2}{*}{1} & Sekolah Dasar (Primary & 1.545 & 905 & 2.450 \\
\hline & Schools)-SD & & & \\
\hline \multirow[t]{3}{*}{2} & Menengah & 107 & 906 & 1.013 \\
\hline & Pertama (Junior High & & & \\
\hline & Schools) - SMP & & & \\
\hline \multirow[t]{3}{*}{3} & Sekolah Menengah Atas & 49 & 230 & 279 \\
\hline & (Senior High Schools) - & & & \\
\hline & SMA & & & \\
\hline \multirow[t]{2}{*}{4} & Menengah & 11 & 345 & 356 \\
\hline & Kejuruan (SMK) & & & \\
\hline
\end{tabular}

Sumber: Kabupaten Bogor dalam Angka (2018)

Table 1 di atas menunjukkan pada tingkat sekolah dasar negeri lebih banyak dari pada sekolah dasar swasta. Sedangkan pada tingkat pendidikan yang lain dari mulai SMP, SMA dan SMK menunjukkan bahwa sekolah negeri lebih sedikit dari pada sekolah swasta. Sedangkan berdasarkan jumlahnya dapat digambarkan bahwa semakin tinggi tingkat pendidikan semakin sedikit jumlah sekolah yang tersedia baik negeri atau pun swasta.

Table 2. Jumlah Sekolah Pendidikan Khusus SLB di Kabupaten Bogor, 2017

Number of Special Education Schools SLB and SDLB in Bogor Regency, 2017

\begin{tabular}{clcccc}
\hline No & Tingkat/ Status & Negeri & Swasta & Jumlah \\
\hline 1 & $\begin{array}{l}\text { Sekolah } \\
\text { Biasa (SLB) }\end{array}$ & Luar & 1 & 5 & 6 \\
& & & &
\end{tabular}

Sumber: Kabupaten Bogor dalam Angka (2018)

Pada table 2 di atas tentang sekolah pendidikan khusus di kabupaten Bogor, data menunjukkan SLB Negeri hanya ada 1 sekolah, sedangkan SLB Swasta sebanyak 6 sekolah. Sedangkan pada tabel 3 di bawah ini menunjukkan data sekolah nonformal, yaitu berupa sekolah kursus, PKBM dan SKB.

Table 3. Jumlah Sekolah Nonformal di Kabupaten Bogor, 2017

Number of Nonformal Schools in Bogor Regency, 2017

\begin{tabular}{clcccc}
\hline No & Tingkat/ Status & Negeri & Swasta & Jumlah \\
\hline 1 & Kursus & 0 & 57 & 57 \\
2 & $\begin{array}{l}\text { Pusat } \\
\text { Belajar }\end{array}$ & 0 & 169 & 169
\end{tabular}


Masyarakat

(PKBM)

$3 \mathrm{SKB}$

Sumber: Kabupaten Bogor dalam Angka (2018)

Sekolah kursus dan PKBM di Kabupaten Bogor tidak ada satu pun yang berstatus negeri. Sedangkan SKB hanya ada satu lembaga dan berstatus negeri.

\section{Pembahasan}

Upaya peningkatan partisipasi masyarakat pada pendidikan di Kabupaten Bogor harus dilakukan, karena data tahun 2018 menunjukkan bahwa rata-rata lama sekolah (RLS) di Kabupaten bogor masih rendah yaitu 7,82 tahun. Hal tersebut dapat dilakukan dengan meningkatkan kemudahan dalam akses pendidikan untuk semua kalangan, terutama masyarakat pedesaan yang tingkat ekonominya menengah ke bawah.

Berbagai upaya dilakukan oleh pemerintah Kabupaten Bogor untuk meningkatkan aksesibilitas pendidikan sehingga diharapkan meningkatkan RLS, meliputi pembangunan Ruang Kelas Baru (RKB) atau rehabilitas sekolah. Hal ini merupakan strategi pertama yang dilakukan dalam upaya meningkatkan RLS di kabupaten Bogor. Selain itu, strategi lain yang dibuat berupa penguatan sekolah alternatif (sekolah terbuka, kelas jauh dan satu atap), mengaktifkan kelompok PKBM, dan mendorong pendidikan kesetaraan (paket A,
B, C) serta mengkatifkan program Keaksaraan Fungsional (KF).

Meningkatkan koordinasi dan kerjasama dengan sekolah swasta sebagai upaya untuk memperluas jangkauan kegiatan belajar mengajar, hal ini karena ketersediaan sekolah negeri sangat terbatas. Berbagai macam upaya pemerintah Kabupaten Bogor lakukan untuk meningkatkan RLS.

Selain itu juga merintis kembali dan membangun gerakan Desa Mengajar yang bekerjasama dengan pondok pesantren salafi pada desa-desa prioritas yang angka RLSnya masih rendah. sekaligus mengaktifkan kembali SATGAS sekolah untuk mengawasi, mendata sekaligus melaporkan anak-anak yang putus atau tidak sekolah. Sehingga dapat diberikan tindakan dengan cepat dan akurat.

Kaitannya dengan peran perguruan tinggi di Kabupaten Bogor, maka pemerintah melakukan kerjasama dengan perguruan tinggi yang ada dalam upaya peningkatan pemahaman masyarakat terhadap pentingnya pendidikan atau bersekolah melalui kegiatan pengabdian pada masyarakat oleh dosen juga sekaligus melibatkan mahasiswa melalui kegiatan Kuliah Kerja Nyata (KKN).

Meskin demikain, namun tetap saja masih banyak masalah sosial yang berdampak pada partisipasi masayarakat pada pendidikan. Strategi yang telah dibuat dan dirancang boleh jadi tidak semuanya dapat menjadi solusi 
permasalah sosial tersebut, atau bahkan belum mengakomodasi semua kebutuhan/tuntutan masyarakat (social demand). Maka disinilah sebuah data yang akurat tentang permasalah sosial dan social demand di Kabupaten Bogor untuk dapat merumuskan strategi baru atau memilih strategi prioritas agar dapat menjadi solusi permasalahan.

Berbagai alasan dan penyebab mengapa masyarakat tidak dapat sekolah dan atau putus sekolah di Kabupaten Bogor, diantaranya adalah:

1. Tidak ada biaya/biaya yang tidak terjangkau, meskipun saat ini ada Biaya Operasional Sekolah (BOS) dari pemerintah, tetap saja masyarakat harus menyiapkan dana untuk perlengkapan sekolah seperti, buku, baju sekolah dan bahkan uang transport karena jarak sekolah yang jauh;

2. Tingginya minat masuk pondok pesantren tradisional, dan hal ini juga sebagai peralihat karena tidak mampunya membiayai sekolah di sekolah formal;

3. Seorang anak dari keluarga tidak mampu lebih memilih bekerja karena ingin membantuk perekonomian keluarga;

4. Bullying di Sekolah yang menyebabkan ketakutan dan rasa tidak aman;

5. Anak tidak mau sekolah dibarengi dengan kurangnya perhatian dari orang tua terhadap hal tersebut (perhatian);

6. Pergaulan yang tidak baik, seperti bergaul dengan anak-anak yang malas sekolah bahkan tidak sekolah.

7. Menikah bagi perempuan, karena ada anggapan bahwa seorang perempuan yang sekolah tinggi atau tidak pada akhirnya juga akan menjadi mengurus anak dan pekerjaan rumah lainnya.

8. Lingkungan masyarakat yang memandang jika tidak sekolah bukah hal yang memalukan.

Dalam perspektif legal, mengakses dan meningkatkan pendidikan merupakan hak semua warga negara sepanjang hayat telah dituangkan dalam UU. Bahkan pemerataan pendidikan menjadi program prioritas pemerintah pusat maupun pemerintah daerah. Namun keterbatasan masyarakat dalam biaya menjadi masalah utama untuk mengakses pendidikan. Sehingga ini menimbulkan tuntutan serta kebutuhan yang harus dipenuhi pemerintah agar meningkatnya partisipasi masyarakat terhadap pendidikan, juga masalah-masalah tambahan lainnya.

Melihat banyaknya permasalah sosial tersebut, menyebabkan banyak pula tuntutan masyarakat kepada pemerintah sebagai dampaknya. Berdasarkan penelitian setidaknya ada 5 aspek social demand yang menjadi PR pemerintah untuk dapat 
diselesaikan melalui kebijakan dan programprogramnya di masa yang akan datang, yaitu:

1. Aspek finansial

2. Aspek sarana dan prasarana

3. Aspek SDM (Guru dan Tenaga Kependidikan)

4. Aspek lingkungan sekolah

5. Aspek vokasi (pendampingan)

Kelima aspek ini menjadi tuntutan masyarakat Kabupaten Bogor, dimana aspek finansial merupakan tuntutan utamanya. Hal ini terjadi karena, penyebab tertinggi masyarakat Kabupaten Bogor adalah kurangnya biaya, sedangkan pandangan masyarakat biaya pendidikan semakin tinggi sehingga tidak terjangkau. Ditambah peralatan sekolah seperti buku LKS, buku tema, seragam sekolah dan perlengkapan lainnya juga menjadi masalah tersendiri dari aspek finansial.

Biaya transport merupakan masalah lain dari aspek finansial, karena ini bersinggungan dengan aspek serana dan prasarana pendidikan di Kabupaten Bogor. Jarak sekolah yang terlalu jauh dari rumah menggambarkan masih kurangnya sarana prasarana pendidikan yang dikebutuhan masyarakat, ditambah masih adanya sekolah yang bergabung dengan sekolah lain.

Pada aspek SDM, masyarakat menuntut ketersediaan guru dan tenaga kependidikan yang berkualitas dengan harapan lulusan dari setiap sekolah mampu bersaing dengan lulusan sekolah lainnya. Apalagi di era digital saat ini, menjadi penting guru dan tenaga kependidikan yang berkualitas yang dibarengi dengan melek teknologi. Hal ini juga sejalan dengan program Bogor Cerdas (Bodas) yang dicanangkan oleh Bupati Bogor.

Tuntutan masyarakat pada aspek lingkungan sekolah yang aman dan nyaman merupakan dampak dari adanya bullying di sekolah yang menyebabkan anak menjadi takut untuk sekolah dan akhirnya drop out. Berdasarkan data KPAI tahun 2019 kasus kekerasan dan bullying di sekolah semakin tinggi dan meresahkan, pada Januari sampai April 2019 tercatat sebanyak 37 kasus kekerasan dan bullying terjadi di sekolah (Rahayu, 2019).

Kebutuhan atau tuntutan yang terakhir adalah aspek vokasi (pendampingan) dapat juga dalam bentuk sosialisasi pentingnya pendidikan kepada masyarakat Kabupaten Bogor, karena banyak masyarakat Kabupaten Bogor yang tidak berminat sekolah di sekolah formal. Malah lebih memilih untuk belajar di pesantren tradisional.

\section{KESIMPULAN DAN IMPLIKASI}

\section{Kesimpulan}

Masalah sosial dalam aksesibilitas pendidikan di Kabupaten Bogor masih didomonasi oleh masalah finansial (dana). Hal tersebut menjadi masalah utama dalam tingkat patisipasi 
masyarakat terhadap pendidikan. Sehingga Rata-rata Lama Sekolah (RLS) di Kabupaten Bogor yang masih rendah didominasi oleh masalah tersebut. Selain itu juga terdapat masalah sosial yang lainnya, seperti minat, lingkungan, dan orientasi individu. Namun masalah itu hanya bagian kecil saja.

\section{Implikasi}

Hasil ini diharapkan dapat menjadi acuan bagi pemerintah Kabupaten Bogor dalam membuat kebijakan yang lebih sesuai dengan permasalah dan kebutuhan yang ada di masyarakat, sehingga dapat meningkatkan partisipasi masyarakat dalam pendidikan yang pada akhirnya akan meningkatkan RLS dan mewujudkan program Bogor Cerdar (Bodas) dengan output insan cendekia yang pintar secara IPTEK juga IMTAQ.

\section{DAFTAR PUSTAKA}

BAPPEDALITBANG. (2018). Kebijakan Pemerintah Kabupaten Bogor di Sektor Pendidikan. Bogor: Tidak Diterbitkan.

Badan Pusat Statistika (BPS). (2018). Kabupaten Bogor Dalam Angka (Bogor Regency in Figure) 2018. http://bogorkab.bps.go.id.

Coombs, P.H. (1982). Apakah Perencanaan Pendidikan itu? Jakarta: Bahratara Karya Aksara.

Rahayu, C.M. (2017). Berita. Retrieved Agustus 31, 2018, from detiknews: www.m.detik.com

Release Diskominfo Kabupaten Bogor. (2019). Pemkab Bogor Resmi Luncurkan Program Bogor Cerdas dan Bogor Berkeadaban website: http://www.bogorkab.go.id diakses tanggal 21 Agustus 2019.

Sa'ud, U. S., \& Makmun, A. S. (2011). Perencanaan Pendidikan. Bandung: Remaja Rosdakarya.

Sugiyono. (2015). Metode Penelitian Pendidikan, Pendekatan Kuantitatif, Kualitatif, dan R\&D. Bandung: Alfabeta. 